\title{
Modeling Airport Ground Access Mode Choice by Trip Purpose: Business vs. Personal Trips
}

\author{
Gurkan Gunay \\ ggunay@dogus.edu.tr \\ Dogus University, Istanbul, Turkey \\ Ilgin Gokasar \\ ilgin.gokasar@boun.edu.tr \\ Bogazici University, Istanbul, Turkey
}

\begin{abstract}
Air transportation traffic is increasing, and this results in newer and larger airport investments in outskirts of the cities. Thus, airport ground access is becoming an important topic to focus on. Indeed, there are many studies in this field covering the mode choices of passengers to and from the airports. In this case study, the mode choices of travelers who are residents of Istanbul for access to Sabiha Gokcen International Airport (SAW) are modeled. To collect data, a revealed-preference survey with passengers is conducted at SAW. A literature review indicated that as well as other factors, trip purpose as business or personal affected the airport ground access mode choice. In accordance with this finding, separate mode choice models for both business and non-business passengers, as well as a pooled model for all travelers are built. Multinomial Logit (MNL) is used to model the mode choices. The modes were automobile, taxi and public transit. The results indicated that trip cost to SAW, traveling group size, time difference between the departure time and flight time, and automobile ownership status of the passenger were the explanatory variables for mode choice model. A market segmentation analysis results further showed that building separate models for business and non-business passengers was an improvement over the pooled mode choice model.
\end{abstract}

Keywords: Airport access; Mode choice; Multinomial logit; Market segmentation; Business vs. Non-business trip

\section{INTRODUCTION AND BACKGROUND}

Increase in population of the cities causes problems in transportation, since number of trips will increase and result in congestion. Istanbul suffers from traffic problems a lot (TOMTOM 2017); and this suffering affects the trips between the city and its airports. There are many studies focused on the airport access, and this work is a case study related to airport access mode choice.

Istanbul has three airports: Ataturk International Airport (ISL), Istanbul Airport (IST), and Sabiha Gokcen International Airport (SAW). SAW is in the Asian side of the city and $44 \mathrm{~km}$ from Taksim, the city center. This makes SAW geographically far from the city center. However, SAW is located next to the major E-80 (TEM) highway, which connects Istanbul to the eastern parts of Turkey. Hence, access to SAW can be considered as easy. SAW was opened in 1999. In 2009, a new terminal with a capacity of 25,000,000 passengers replaced the old terminal. In 2016, 30,000,000 passengers used this airport, 
exceeding the capacity. Unlike IST, SAW serves mostly as an origin-destination airport. Locations of IST, ISL and SAW are shown in Figure 1.

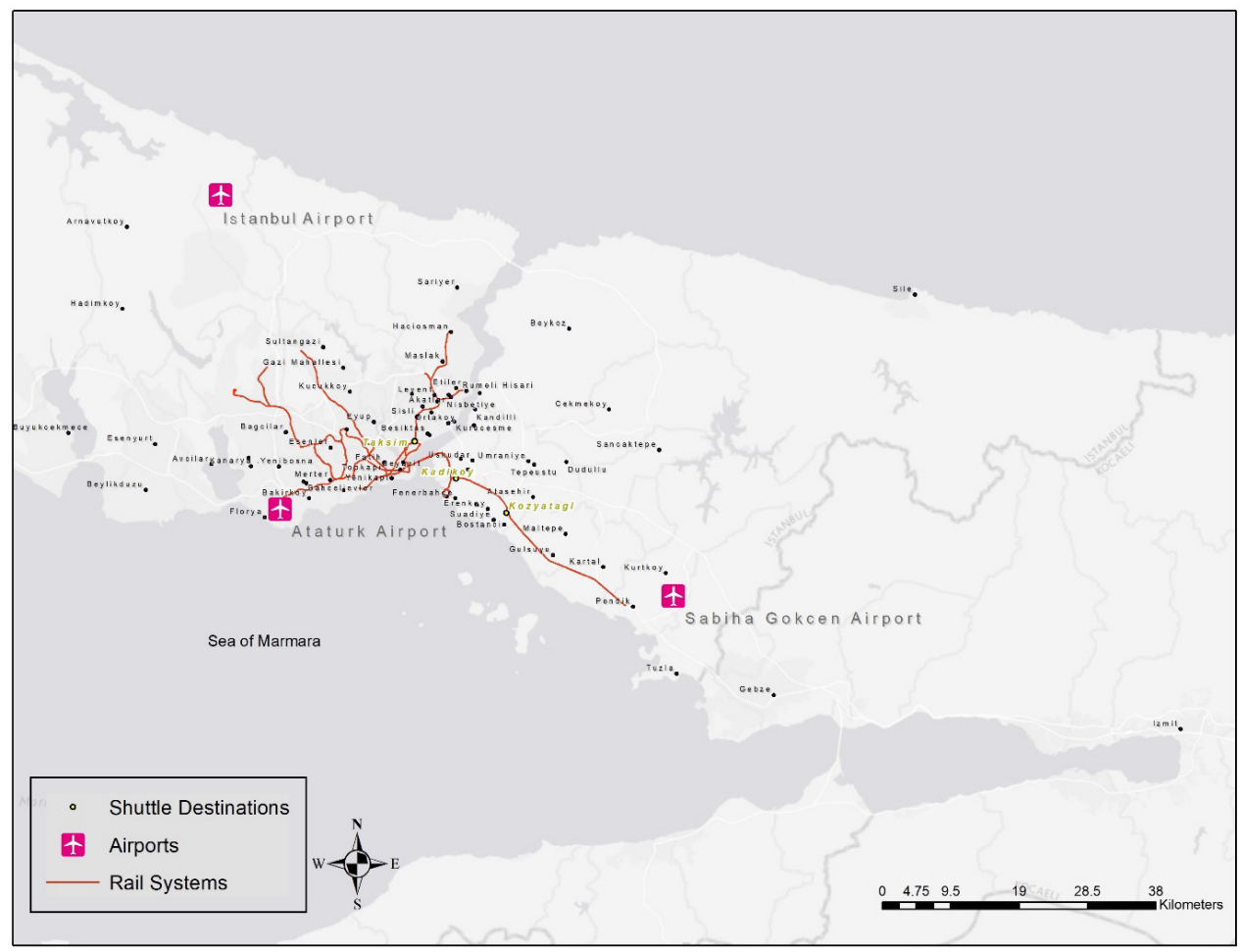

Figure 1: Map Showing IST, ISL and SAW

As it has also been mentioned before, there has been many studies on this field. Different modeling techniques such as Multinomial Logit, Nested Logit and Mixed Logit were applied to model the airport access mode choice behavior of passengers. In those studies, several explanatory variables were determined for airport access mode choice. These variables are namely travel time to the airport, travel cost to the airport, time difference between the departure time and flight time, travel purpose, domestic or international travel, amount of luggage, car ownership status, age of the passenger, gender and income level (Harvey, 1986; Monteiro \& Hansen, 1996; Psaraki \& Abacoumkin, 2002; Hess \& Polak, 2006; Gupta et al., 2008; Tam et al., 2008; Alhussein, 2011; Jou et al., 2011; Akar, 2013; Choo et al., 2013; Zaidan \& Abulibdeh, 2018). Travel purpose as business or non-business is particularly important for choosing private vehicle over public transit. It was found that passengers making business trips choose private vehicles to access the airports (Choo et al., 2013; Zaidan \& Abulibdeh, 2018). Similarly, increasing number of carried luggage causes shift from public transit to private vehicle modes (Tam et al., 2008; Akar, 2013; Zaidan \& Abulibdeh, 2018). However, this effect of luggage was not observed in some other studies; the high number of luggage did not deter passengers from using public transit in those cases (Gokasar \& Gunay, 2017). Another factor for airport access mode choice is being close to a transit station. Rail transit is preferred if 
the passenger's origin point was located within 1/2 miles from the station (Gokasar \& Gunay, 2017).

Several studies developed different models for business and non-business passengers before (Harvey, 1986; Tam et al., 2008; Choo et al., 2013). However, they did not show the importance of segmentation quantitatively. In this study, a market segmentation analysis was made using likelihood ratio test statistic to test the segmentation.

In this case study, it was aimed to show the following:

- A pooled model for airport access mode choice,

- Separate airport access mode choice models for business and personal trip purposes, and

- Superiority of segmented models over the pooled model using likelihood ratio test statistic.

\section{DATA AND THEORY}

\subsection{Data}

Data was collected by conducting a survey with passengers at departures hall of SAW during one weekday in January 2015. Two three-hour sessions were held for data collection. The sessions were held during peak hours, 10:00-13:00 and 17:00-20:00. Sampling method was convenience sampling. A total of 251 interviews were collected. In the interviews, information about passengers' type of travel destination as domestic or international, time difference between their departure time and flight time (TDDF), travel purpose as business or personal, traveling group size, number of luggage and trip cost, time and access mode to SAW were collected. In addition to these, demographics of passengers such as age, gender, income level, education level and automobile ownership status were also obtained. Descriptive statistics revealed that $100(39.8 \%)$ of the passengers were business travelers, and the remaining $151(60.2 \%)$ passengers were traveling for personal purposes. $143(57 \%)$ passengers owned an automobile, and automobile ownership was used as a dummy variable in the models. As it will also be explained in Section 3, most of the other variables were revealed insignificant at 95\% level of confidence.

\subsection{Theory}

In this study, to model the airport access mode choice, discrete choice theory was used. Specifically, from the discrete choice modeling family, multinomial logit (MNL) model was applied. Discrete choice models use the maximization of utility, $U$, of users as basis. Below is the mathematical expression for user $i$ on the mode $j$ in choice set $C_{i}$ (Ben-Akiva \& Lerman, 1985):

$$
P_{i}(j)=\operatorname{Pr}\left(U_{j i} \geq U_{l i}, \forall l \in C_{i}\right)
$$

The utility function has two parts as deterministic, $V$; and random, e :

$$
U_{j i}=V_{j i}+\mathrm{e}_{j i}
$$


The deterministic part of the utility function is linear; and can be expressed as:

$$
V_{j i}=\hat{\mathbf{a}}_{\mathbf{i}} \mathbf{x}_{\mathbf{j i}}
$$

, where $\hat{\mathbf{a}}_{\mathbf{i}}$ is the coefficient matrix and $\mathbf{x}_{\mathbf{j i}}$ is the vector of independent variables. Probability of individual $i$ 's choosing mode $j P_{i}(j)$ is:

$$
P_{i}(j)=\frac{\exp \left(V_{j i}\right)}{\sum_{l \in C_{i}} \exp \left(V_{l i}\right)}
$$

In this study, three different MNL models were developed. First one for all passengers, second one for only business passengers and the third one for the remaining passengers; that is, passengers making personal trips. The last two models were segmented models; and the improvement of segmentation over the pooled model was checked using the loglikelihood (LL) values of the three models. The likelihood ratio test statistic (LRTS) was computed, which had a chi-squared distribution. LRTS is used to test the null hypothesis stating that "segmentation did not improve the fit". If the null hypothesis is rejected, then segmentation would not improve the fit. The LRTS formula is given by:

$$
L R T S=-2 * L L(\beta)+2 \sum_{G} L L\left(\beta^{G}\right)
$$

, where $L L(\mathrm{~b})$ is the log-likelihood of the pooled model and $L L\left(\mathrm{~b}^{G}\right)$ is the loglikelihood of the model for segment $G$.

Several assumptions about the costs of trip modes were made for modeling purposes. These were explained as the following:

- Cost of automobile: In the models, automobile mode had two types. First, the passenger drove on his/her own. Second type is that the passenger was dropped off at the airport by someone else. Cost of first auto travel type only included the fuel cost. The average fuel cost per km in Istanbul was assumed to be as $0.34 \mathrm{TL}$ (Gokasar \& Gunay, 2017). Drop-off travel type involved no cost for the passenger. To incorporate these costs, weighted average was used. Descriptive statistics of the data indicated that $40 \%$ of the auto travelers drove on their own, while the remaining $60 \%$ were dropped off. These percentages were used to calculate weighted average of driving and drop-off costs.

- Cost of public transit: Public transit modes were made of shuttle buses and public transit buses. In 2015, average shuttle bus cost was 13 TL between the city and SAW (Havabus, 2017). On the other hand, using public buses involved several connections to access SAW from different locations in Istanbul. At each connection, a fee was paid. The fare structure of public transit system of Istanbul in 2015 is given in Table 1. According to the descriptive statistics, $43 \%$ of the public transit users opted for public buses. Again, weighted averages were used. It was assumed that cost of average public bus and connections to other modes would be $6 \mathrm{TL}$. Weighted average of this cost with the shuttle cost yielded in $10.4 \mathrm{TL}$. 
Table 1: Public Transit Rates in Istanbul in 2015 (IETT, 2015)

\begin{tabular}{|c|c|c|c|}
\hline & Full & Elderly Passenger & Student \\
\hline First Ride & 2.3 & 1.65 & 1.15 \\
\hline 1st Connection & 1.65 & 0.95 & 0.5 \\
\hline 2nd Connection & 1.25 & 0.75 & 0.45 \\
\hline 3rd Connection & 0.85 & 0.5 & 0.4 \\
\hline 4th Connection & 0.85 & 0.5 & 0.4 \\
\hline 5th Connection & 0.85 & 0.5 & 0.4 \\
\hline
\end{tabular}

- Cost of taxi: In Istanbul, the taxi tariff in Istanbul was as the following (Istanbul Metropolitan Municipality Directorate of Public Transportation Services, 2016):

$$
R=3.2+2(\text { Distance in } \mathrm{km})+0.325(\text { Travel time in minutes })
$$

Eq. (6) was used to calculate the taxi cost for passengers, since each passenger's origin in Istanbul and their trip times to SAW were collected during survey. Distances between SAW and the origin points were calculated using Google Maps.

\section{ANALYSIS AND RESULTS}

Three MNL models were given in this section: Pooled model for all passengers, and two models for business and non-business passenger segments. Table 2 shows the pooled model below. McFadden $\mathrm{R}^{2}$ was 0.148 ; and all variables were significant at $95 \%$ level of confidence, except automobile ownership and group size for the utility function of public transit. This could be expected though; automobile ownership status not necessarily affects the choice of public transit over taxi. Also, it can be observed that not driving an automobile decreased the choice of automobile over taxi, obviously. Further, travel cost decreased the likelihood of choice of auto or public transit over taxi. As the traveling group size increased, one would less likely choose taxi over automobile. Finally, TDDF was significant for the choice between public transit and taxi. Coefficient of this variable was positive; hence, a passenger is more likely to choose public transit over taxi if they leave for the airport early. It should also be noted that other variables in the data such as income level of the passenger, gender, or amount of luggage were insignificant; hence, they were omitted. 
Table 2: Pooled Model

\begin{tabular}{|c|c|c|c|}
\hline & & \multicolumn{2}{|c|}{ Model } \\
\hline \multicolumn{2}{|c|}{ Variables Specific to Alternatives } & Coefficient & Significance \\
\hline \multicolumn{2}{|c|}{ Travel Cost } & -0.014 & 0.011 \\
\hline \multirow{4}{*}{ Auto } & Constant & -0.503 & 0.485 \\
\hline & No Auto Ownership & -1.225 & 0.005 \\
\hline & Group Size & 0.402 & 0.048 \\
\hline & TDDF & -0.003 & 0.560 \\
\hline \multirow{4}{*}{ Public Transit } & Constant & -2.867 & 0.000 \\
\hline & No Auto Ownership & 0.198 & 0.581 \\
\hline & Group Size & 0.319 & 0.106 \\
\hline & TDDF & 0.014 & 0.002 \\
\hline \multicolumn{2}{|c|}{$\mathrm{LL}(\mathrm{c})$} & \multicolumn{2}{|c|}{-254.899} \\
\hline \multicolumn{2}{|c|}{ LL(B) } & \multicolumn{2}{|c|}{-217.060} \\
\hline \multicolumn{2}{|c|}{ Chi-squared Test Statistic } & \multicolumn{2}{|c|}{75.678} \\
\hline \multicolumn{2}{|c|}{ Significance } & \multicolumn{2}{|c|}{0.000} \\
\hline \multicolumn{2}{|c|}{ McFadden R2 } & \multicolumn{2}{|c|}{0.148} \\
\hline \multicolumn{2}{|c|}{ Adjusted McFadden R2 } & \multicolumn{2}{|c|}{0.133} \\
\hline \multicolumn{2}{|c|}{ Number of Observations } & \multicolumn{2}{|c|}{251} \\
\hline
\end{tabular}

MNL model for business travelers was given in Table 3. This model had interesting results compared to the pooled model: Only the generic variable, travel cost, was significant at $95 \%$ level of confidence. It had a negative coefficient, which meant that its increase would result in a decrease in likelihood of choosing auto or public transit modes over taxi. Other variables, which were auto ownership and traveling group size, were insignificant. However, these variables were kept here for consistency between the pooled and segmented models, to compute the LRTS.

Table 3: Model for Business Travelers

\begin{tabular}{|c|c|c|c|}
\hline \multirow{2}{*}{\multicolumn{2}{|c|}{ Variables Specific to Alternatives }} & \multicolumn{2}{|c|}{ Model } \\
\hline & & Coefficient & Significance \\
\hline \multicolumn{2}{|c|}{$\begin{array}{l}\text { Travel Cost } \\
\end{array}$} & -0.020 & 0.026 \\
\hline \multirow{4}{*}{ Auto } & Constant & -0.353 & 0.714 \\
\hline & No Auto Ownership & -0.705 & 0.322 \\
\hline & Group Size & 0.383 & 0.265 \\
\hline & TDDF & -0.006 & 0.325 \\
\hline \multirow{4}{*}{ Public Transit } & Constant & -2.574 & 0.012 \\
\hline & No Auto Ownership & 0.849 & 0.172 \\
\hline & Group Size & -0.323 & 0.436 \\
\hline & TDDF & 0.008 & 0.164 \\
\hline \multicolumn{2}{|c|}{ LL(c) } & \multicolumn{2}{|c|}{-106.654} \\
\hline \multicolumn{2}{|c|}{ LL(B) } & \multicolumn{2}{|c|}{-91.312} \\
\hline \multicolumn{2}{|c|}{ Chi-squared Test Statistic } & \multicolumn{2}{|c|}{30.684} \\
\hline \multicolumn{2}{|c|}{ Significance } & \multicolumn{2}{|c|}{0.000} \\
\hline \multicolumn{2}{|c|}{ McFadden R2 } & \multicolumn{2}{|c|}{0.144} \\
\hline \multicolumn{2}{|c|}{ Adjusted McFadden R2 } & \multicolumn{2}{|c|}{0.104} \\
\hline \multicolumn{2}{|c|}{ Number of Observations } & \multicolumn{2}{|c|}{100} \\
\hline
\end{tabular}

Table 4 shows the MNL model for passengers who make personal trips (non-business passengers). McFadden $\mathrm{R}^{2}$ was 0.144 , and interestingly, unlike the model for business 
passengers, travel cost to the airport was insignificant at $95 \%$ level of confidence in this model. For the choice of automobile over taxi, not owning an automobile decreased its likelihood, while a large traveling group size increased its probability. On the other hand, a large group is more likely to choose public transit over taxi. About TDDF, similar to the case in pooled model, it can be said that a passenger will leave early if the mode choice is public transit rather than taxi.

Table 4: Model for Travelers Making Personal Trips

\begin{tabular}{|c|c|c|c|}
\hline & & \multicolumn{2}{|c|}{ Model } \\
\hline \multicolumn{2}{|c|}{ Variables Specific to Alternatives } & Coefficient & Significance \\
\hline \multicolumn{2}{|c|}{ Travel Cost } & -0.010 & 0.182 \\
\hline \multirow{4}{*}{ Auto } & Constant & -1.103 & 0.351 \\
\hline & No Auto Ownership & -1.374 & 0.020 \\
\hline & Group Size & 0.579 & 0.047 \\
\hline & TDDF & 0.001 & 0.869 \\
\hline \multirow{4}{*}{ Public Transit } & Constant & -3.581 & 0.000 \\
\hline & No Auto Ownership & -0.299 & 0.531 \\
\hline & Group Size & 0.544 & 0.049 \\
\hline & TDDF & 0.021 & 0.002 \\
\hline \multicolumn{2}{|c|}{ LL(c) } & \multicolumn{2}{|c|}{-141.714} \\
\hline \multicolumn{2}{|c|}{ LL(B) } & \multicolumn{2}{|c|}{-117.626} \\
\hline \multicolumn{2}{|c|}{ Chi-squared Test Statistic } & \multicolumn{2}{|c|}{48.175} \\
\hline \multicolumn{2}{|c|}{ Significance } & \multicolumn{2}{|c|}{0.000} \\
\hline \multicolumn{2}{|c|}{ McFadden R2 } & \multicolumn{2}{|c|}{0.170} \\
\hline \multicolumn{2}{|c|}{ Adjusted McFadden R2 } & \multicolumn{2}{|c|}{0.145} \\
\hline \multicolumn{2}{|c|}{ Number of Observations } & \multicolumn{2}{|c|}{151} \\
\hline
\end{tabular}

Finally, to check if the segmentation improved the fit over the pooled model; the LRTS was computed. Using Eq. (1), the LRTS was revealed 16.243. The tabular value of this statistic for 4 degrees of freedom and 5\% level of significance was 9.49; hence, it was smaller than the calculated value. Thus, it was concluded that the null hypothesis "segmentation did not improve the fit" could be rejected at 95\% level of confidence. Therefore, segmentation improved the fit over the pooled model.

\section{CONCLUSION}

In this case study, airport ground access mode choice for SAW Airport in Istanbul was investigated. Three MNL models were built for all passengers, business travelers and passengers making personal trips, respectively. A market segmentation analysis was carried out; and it was understood that building segmented airport access mode choice models proved a better fit than pooled model. Further, the need of segmentation was also visible due to the significant variable types in the segmented models. This is because only trip cost was significant for the MNL model for business passengers, and that variable was insignificant for passengers making personal trips. For the nonbusiness passengers, traveling group size, TDDF, and auto ownership status variables were significant. Hence, this study's results are in conjunction with the work of (Harvey, 1986), (Tam et al., 2008) and (Choo et al., 2013), since they developed different models 
for business and non-business passengers. However, this study is different from them in terms of explanatory variables. Those studies used variables related to number of luggage, age of the passenger, and travel time to the airport in addition to the travel cost. However, those variables were insignificant in this study. Further, in this work, market segmentation test was used to show the necessity of segmentation, something the other studies did not use.

Future research may focus on the stated preferences of passengers in case of a new mode's introduction for the trips between SAW and Istanbul. With the help of stated preferences, the interest in the new mode can be understood and strategies related to that mode can be developed accordingly.

\section{REFERENCES}

Akar, G. (2013). Ground access to airports, case study: Port Columbus International Airport. Journal of Air Transport Management, 30, 25-31.

Alhussein, S. N. (2011). Analysis of ground access modes choice King Khaled International Airport, Riyadh, Saudi Arabi. Journal of Transport Geography, 19, 6, 1361-67.

Ben-Akiva, M. \& Lerman, S. (1985). Discrete choice analysis: Theory and application to travel demand. MIT Press, Cambridge, MA.

Choo, S., You, S. \& Lee, H. (2013). Exploring characteristics of airport access mode choice: A case study of Korea. Transportation Planning and Technology, 36, 4, 335-51.

Gokasar, I. \& Gunay, G. (2017). Mode choice behavior modeling of ground access to airports: A case study in Istanbul, Turkey. Journal of Air Transport Management, 59, 1-7.

Gupta, S., Vovsha, P. \& Donnelly, R. (2008). Air passenger preferences for choice of airport and ground access mode in the New York City, Metropolitan Region. Transportation Research Record: Journal of the Transportation Research Board, 2042, 1, 3-11.

Harvey, G. (1986). Study of airport access mode choice. Journal of Transportation Engineering, $112,5,525-545$.

Havabus (2017). Havabus. Retrieved July 23, 2017 (www.havabus.com).

Hess, S. \& Polak, J. W. (2006). Airport, airline and access mode choice in the San Francisco Bay Area. Papers in Regional Science, 85, 4, 543-567.

IETT (2015). IETT Public Transit Rates (in Turkish). Retrieved February 25, 2017 (http://www. iett.istanbul/tr/main/pages/toplu-tasima-ucret-tarifesi/42).

Istanbul Metropolitan Municipality Directorate of Public Transportation Services. (2016). Taksi Taşımacılı̆̆ Taksimetre Ücret Tarifeleri (in Turkish). Retrieved from https://tuhim.ibb.gov. tr/media/2147/taksi-tas- $\% \mathrm{C} 4 \% \mathrm{~B} 1 \mathrm{mac} \% \mathrm{C} 4 \% \mathrm{~B} 11 \% \mathrm{C} 4 \% \mathrm{~B} 1 \mathrm{~g}-\% \mathrm{C} 4 \% \mathrm{~B} 1$-taksimetre-u-crettarifeleri.pdf.

Jou, R. C., Hensher, D. A. \& Tzu, L. H. (2011). Airport ground access mode choice behavior after the introduction of a new mode: A case study of Taoyuan International Airport in Taiwan. Transportation Research Part E: Logistics and Transportation Review, 47, 3, 371-381.

Monteiro, A. B. F. \& Hansen, M. (1996). Improvements to airport ground access and behavior of multiple airport system: BART extension to San Francisco International Airport. Transportation Research Record, 1562, 38-47.

Psaraki, V. \& Abacoumkin, C. (2002). Access mode choice for relocated airports: The New 
Athens International Airport. Journal of Air Transport Management, 8, 2, 89-98.

Tam, M. L., Lam, W. H. K. \& Lo, H. P. (2008). Modeling air passenger travel behavior on airport ground access mode choices. Transportmetrica, 4, 2, 135-53.

TOMTOM (2017). TOMTOM Traffic Index - Full Ranking. https://www.tomtom.com/en_gb/ trafficindex/list?citySize $=$ LARGE\&continent=ALL\&country $=$ ALL .

Zaidan, E. \& Abulibdeh, A. (2018). Modeling ground access mode choice behavior for Hamad International Airport in the 2022 FIFA World Cup City, Doha, Qatar. Journal of Air Transport Management, 73, 32-45. 